Contemporary Herpetology

ISSN 1094-2246

2000 Number 4

19 September 2000

\title{
USE OF INHALANT ANESTHETICS IN THREE SNAKE SPECIES
}

Gabriel Blouin-Demers ${ }^{1,3}$, Patrick J. Weatherhead ${ }^{1}$, Catherine M. Shilton ${ }^{2}$, Christopher E. Parent ${ }^{1}$, and Gregory P. Brown ${ }^{1}$

${ }^{1}$ Department of Biology, Carleton University, Ottawa, Ontario, K1S 5B6, Canada

${ }^{2}$ Gananoque Veterinary Clinic, Gananoque, Ontario, K7G 2T6, Canada

3 Email: gblouind@ccs.carleton.ca

Abstract- Different snake species respond differently to various anesthetic agents. Hence, an anesthetic procedure developed for one species cannot necessarily be safely transferred to another species. The goal of this paper is to summarize our experience using inhalant anesthetics on three snake species, including both procedures that were successful and those we found to be less satisfactory. We found isoflurane delivered with a precision vaporizer to be the best agent to anesthetize black rat snakes (Elaphe o. obsoleta). Sex and mass did not seem to affect induction times in black rat snakes, but larger female rat snakes recovered faster from anesthesia than smaller females. Halothane delivered in the open method provided consistent anesthesia in northern water snakes (Nerodia s. sipedon), although it caused some mortality and should not be used on debilitated patients. Halothane delivered with a precision vaporizer may be used to anesthetize eastern massasauga rattlesnakes (Sistrurus $c$. catenatus). However, care must be taken to prevent mortality resulting from anesthetic overdose. Sex and mass had no effect on induction and recovery times in the rattlesnakes, but stressed animals require longer induction and recovery times.

The miniaturization of radio-transmitters has allowed research on snakes to advance significantly in the past 25 years. Several radio-transmitter attachment techniques have been used on snakes including force-feeding (Fitch and Shirer, 1971), surgical implantation (Reinert and Cundall, 1982), and external attachment (Ciofi and Chelazzi, 1991). Because implanted transmitters appear to have the least impact on the behavior of snakes and provide long tracking periods, most researchers now prefer to use transmitters surgically implanted in the coelom (Reinert, 1992). Surgery requires that snakes be anesthetized. When initiating research that involves anesthetizing snakes it would be extremely helpful if methods could be developed based on past research. As a step toward developing a comparative basis for snake anesthesiology, here we report our experiences with anesthetics and delivery systems on three species of snakes. 
Some researchers have used injectable anesthetics to induce anesthesia in reptiles (Karlstrom and Cook, 1955; Betz, 1962; Weatherhead and Anderka, 1984). This technique has several disadvantages, including unpredictable depth of anesthesia and adverse physiological effects (Font and Schwartz, 1989; Bennett, 1991; Frye, 1993; Harvey-Clark, 1995). Inhalant anesthetics are superior to injectable agents because the depth of anesthesia can be controlled accurately and prolonged recovery times associated with injectable agents are avoided (Hackenbrock and Finster, 1963; Bonath, 1979; Reinert and Cundall, 1982; Arena and Richardson, 1990).

Information regarding the use of inhalant anesthetics in reptiles is scarce (Bennett, 1991) and often inadequately reported (McDonald, 1976). In addition, even closely related species can respond very differently to the various anesthetic agents (Bonath, 1979; Aird, 1986; Font and Schwartz, 1989; Arena and Richardson, 1990). Thus, one cannot assume that anesthesia procedures developed for one species can safely be transferred to another species. Veterinary textbooks only give general guidelines regarding reptilian anesthesia (Frye, 1991, 1993), and the few accounts of procedures for specific species are often based on very few animals (Fagella and Raffe, 1987). Furthermore, properly designed comparative experiments to assess the efficacy of several anesthetics under different conditions are not practical when dealing with species that may be hard to catch in sufficient numbers, or even more important, are of conservation concern. Thus, at present, trial and error must be used to determine the appropriate anesthesia procedure for the species of interest. This is likely to result in unnecessary mortality and time loss before a satisfactory technique is developed. Only by collecting anecdotal evidence on the effect of common anesthetic agents on different snake species will it be possible to compile sufficient information to do real comparative analyses. Toward that end we report our experiences (both negative and positive) developing inhalant anesthetic procedures for black rat snakes (Elaphe o. obsoleta), northern water snakes (Nerodia s. sipedon), and eastern massasauga rattlesnakes (Sistrurus c. catenatus).

\section{MATERIALS AND METHODS}

We worked with three commonly used inhalant agents: isoflurane, halothane, and methoxyflurane. Based on its physiological effects, isoflurane is the preferred inhalant agent because it is the least depressing to the cardiovascular system (Bennett, 1991; Harvey-Clark, 1995). Also, isoflurane is the least soluble in blood and tissue, thus producing the fastest anesthetic depth changes. However, isoflurane has a high vapor pressure $\left(33 \%\right.$ at $\left.20^{\circ} \mathrm{C}\right)$ that can result in high concentrations of anesthesia if the open method is used (see Delivery Systems below). Isoflurane is the most expensive agent we consider here (US $\$ 60$ for $100 \mathrm{ml}$ ). Halothane has similar volatility to isoflurane, reaching a maximum concentration of $32 \%$ at $20^{\circ} \mathrm{C}$ (Bennett, 1991). Halothane is slightly more soluble in blood than isoflurane and also results in rapid anesthetic depth changes. Halothane is the cheapest agent to use among the three we consider (US \$10 for $100 \mathrm{ml}$ ). Because methoxyflurane has the lowest vapor pressure and a concentration over $3 \%$ cannot be obtained at $20^{\circ} \mathrm{C}$ (Bennett, 1991), it is the safest inhalant agent to use in the open method. Methoxyflurane is very soluble in blood and 
results in slow anesthetic depth changes. This agent is potent and highly toxic to the renal system. Methoxyflurane is less expensive to use than isoflurane, but more expensive than halothane (US $\$ 212$ for $100 \mathrm{ml}$, but about $90 \%$ less methoxyflurane than isoflurane or halothane is needed to obtain the same results).

Our surgical procedures were similar to those outlined by Reinert and Cundall (1982) and averaged $17 \mathrm{~min}$ (range $=15-20 \mathrm{~min}$ ) from the first incision to the final suture. Unlike Reinert and Cundall (1982), we cut through two ribs to insert the transmitter in the coelom and attached the transmitter to the intact rib posterior to the incision with suture material to prevent its migration in the body cavity after surgery. All surgeries were performed in the laboratory at room temperatures of $25^{\circ} \mathrm{C}$ to $30^{\circ} \mathrm{C}$.

\section{Delivery Systems}

The open method simply involves placing the snake in an airtight vessel containing volatile anesthetic (Reinert and Cundall, 1982). We used this method on black rat snakes and water snakes and followed Bennett's (1991) recommendation of using $5 \mathrm{ml}$ anesthetic per $2840 \mathrm{ml}$ of volume of the induction chamber. We used a $4000 \mathrm{ml}$ plastic jar with a screw-on lid for our induction chamber. We applied the agent to cotton swabs placed in the closed jar for $10 \mathrm{~min}$. We agitated the jar to maximize evaporation of the liquid anesthetic. Because anesthetic agents are heavier than air, their concentration tends to be higher at the bottom of a container. However, our induction vessel was small and the snakes continuously moved during the early stages of induction, providing constant mixing of the anesthetic. Thus, we are confident that the snakes were exposed to a high concentration of the agent.

We placed a snake in the induction jar until it lost its righting reflex. We tested the righting reflex simply by tipping the jar and observing the snake's response. If the snake did not respond to physical stimuli after being removed from the jar, we immediately started ventilating it with a syringe fitted with a catheter (see Recovery from Anesthesia below), continuing throughout the surgery or until muscle tone returned to the tail. Failure to ventilate a deeply anesthetized snake in this manner increased the risk of mortality, since snakes stop breathing under anesthesia and thus suffocate if artificial ventilation is not performed. If a snake responded to physical stimuli when removed from the jar, it reached surgical depth of anesthesia (complete loss of muscle tone, unresponsive to physical stimulus) if left undisturbed for approximately $10 \mathrm{~min}$. This is likely a consequence of the snake holding its breath, causing it to continue absorbing anesthetic from its lungs. In this case, we started ventilating the snake when the body wall was being stitched at the completion of surgery.

The second, and more complicated method of delivering anesthetic was a precision vaporizer, which involves delivering an exact concentration of anesthetic mixed in pure oxygen directly to the snake's lungs, without relying on the snakes voluntarily inhaling the anesthetic. We used this method on black rat snakes and massasauga rattlesnakes. Because snakes have a small lung volume, an anesthetic circuit that minimizes rebreathing of expired gases is desirable. We used a Bain circuit (Concannon, 1996) with 
oxygen flow rate of $400-1000 \mathrm{ml} / \mathrm{kg} / \mathrm{min}$ (Figure 1). The minimum equipment required to deliver an anesthetic with this method is a precision vaporizer specific to the agent being used (each vaporizer is calibrated for a given agent and can only be used with this agent), an oxygen cylinder, an oxygen regulator, an oxygen rotameter, a ventilation bag, a Bain circuit equipped with a scavenge venting out-of-doors, and a catheter used as an endotracheal tube. Cost of this equipment was approximately US $\$ 1200$.

To induce anesthesia in black rat snakes, the patient was placed in a $4000 \mathrm{ml}$ jar with a hole in the lid to accommodate the end of the Bain circuit. We then ran the anesthetic agent using the anesthetic machine into the jar for 2 min to obtain the desired anesthetic concentration. Once the snake was sufficiently relaxed to allow endotracheal intubation (indicated by a slow righting reflex) we removed it from the jar and inserted a catheter in its glottis. For intubation we used a 10 to 14 gauge catheter fitted with an adapter for the Bain circuit. It is important that the catheter fit tightly into the glottis to prevent leakage around the tube. Once the catheter was in place, the snake was ventilated with the mixture of anesthetic and oxygen until no muscle tone remained, at which point the snake no longer responded to surgical stimuli. Because the period of anesthesia required was usually relatively short (less than $20 \mathrm{~min}$ ), we found that the anesthetic could be discontinued at the start of surgery (while continuing ventilation with $100 \%$ oxygen) and still provide anesthesia long enough to perform transmitter implantation. If a longer period of anesthesia was required, the anesthetic percentage was reduced to a maintenance level of $2-2.5 \%$ after induction.

We did not attempt endotracheal intubation in Sistrurus. Instead, we used a modified 35 $\mathrm{ml}$ plastic syringe casing as an induction chamber. The closed end of the syringe casing was cut off and the narrow end of the cylinder was connected to the anesthetic machine by a length of tubing. The open-end of the casing was pushed forward over the anterior third of the snake and the animal held securely within. We molded Plasticine ${ }^{\mathrm{TM}}$ between the snake's body and the side of the casing to seal the induction chamber. To minimize the risk of snakebite, rattlesnakes were held in this apparatus throughout surgery and recovery.

Recovery from Anesthesia Continuing ventilation after anesthesia removes anesthetic from the snake's blood via the lungs and hence accelerates recovery. Thus, in all cases when bringing a snake out of anesthesia following surgery, we used ventilation in conjunction with physical stimulation to promote more rapid recovery. Following anesthesia with the open method, we ventilated black rat snakes and water snakes using a $60 \mathrm{ml}$ syringe fitted with an approximately $15 \mathrm{~cm}$ length of 10 to 14 gauge catheter. The other end of the catheter was placed into the glottis. Inspiration involved filling the syringe with room air which was then delivered to the lungs via the catheter. Expiration occurred naturally by waiting for the lungs to deflate back to their resting size (the room must be well ventilated to avoid health hazards). Following anesthesia with a vaporizer, we ventilated the snakes for 10 min post-surgery with $100 \%$ oxygen using the anesthesia machine. We then switched to manual ventilation (as described above) and physical stimulation, except for Sistrurus, where ventilation was continued with the anesthesia machine until recovery. Physical stimulation consisted of frequently 
changing the snake's body position and gently pinching their skin and tail. We continued ventilation and stimulation until the snake was breathing unaided, its righting reflex and tongue-flicking had returned, and the snake had begun to move freely.

\section{RESULTS}

\section{Elaphe o. obsoleta}

We used isoflurane in a precision vaporizer on 61 black rat snakes $(400-1145 \mathrm{~g})$ a total of 105 times and all recovered (Table 1$)$. We recorded induction and recovery times for 28 of these individuals. We used a $5 \%$ isoflurane concentration for induction in the jar, which took on average $12.6 \mathrm{~min}$ (range $=10-17 \mathrm{~min}$ ). We initially tried inducing the snakes at less than $5 \%$ isoflurane but were unable to achieve surgical anesthesia. After intubation, we continued running $5 \%$ isoflurane and black rat snakes reached surgical depth of anesthesia after $18.2 \mathrm{~min}$ (range $=12-26 \mathrm{~min}$ ). We used ANCOVA to assess the effect of sex and mass on induction time. The interaction term was not significant $(F(1,24)=2.02, p=0.16)$, and was thus eliminated and the analysis repeated. Neither $\operatorname{sex}(F(1,25)=0.40, p=0.53)$ nor mass $(F(1,25)=0.55, p=0.46)$ affected induction time. Recovery was complete (as indicated by the return of breathing and of the righting reflex) after an average of $12.2 \mathrm{~min}$ (range = 1-31 $\mathrm{min}$ ) post-surgery. We used ANCOVA to assess the effect of sex and mass on recovery time. The interaction term $(F(1,24)=$ $7.01, p=0.01$ ), indicated that mass had a different effect on recovery time for males and females. We thus conducted two separate simple linear regression analyses to assess the effect of mass on recovery time. Heavier females recovered significantly faster from anesthesia than lighter females $(r=-0.57, F(1,15)=7.48, p=0.01)$. For males, mass had no significant effect $(r=0.28, F(1,9)=0.81, p=0.39)$ on recovery time.

We used halothane in the open method on seven black rat snakes (510-925 g). Black rat snakes lost their righting reflex and reached surgical depth of anesthesia after 29.6 min (range $=23-33 \mathrm{~min}$ ) spent in the jar (Table 1). However, there was substantial individual variation in the response to this agent. We used the amount of halothane suggested by Bennett (1991) on five black rat snakes $(7 \mathrm{ml}$ of halothane in a $4000 \mathrm{ml}$ jar). It worked well for one snake, two snakes did not revive from anesthesia, and two snakes took over 70 min to recover. We used half this amount of halothane on two snakes and both began to revive in the middle of the surgery. Therefore, it seems that the halothane dosage required to keep black rat snakes at a surgical plane of anesthesia long enough for transmitter implantation is often lethal or requires prolonged recovery periods. Aird (1986) also reported high mortality when using halothane on Crotalus. Halothane appears unsuitable for black rat snake anesthesia.

We used methoxyflurane in the open method and delivered the maximum achievable methoxyflurane concentration by soaking the cotton swab with $15 \mathrm{ml}$ of the agent. The obtained concentration was insufficient to bring two black rat snakes (670 $\mathrm{g}$ and $840 \mathrm{~g}$ ) to a surgical depth of anesthesia (Table 1). The snakes remained very responsive even after 35 and $37 \mathrm{~min}$, respectively, spent in the jar. Thus, this agent appears not to 
provide sufficient anesthesia in black rat snakes, although it has been used successfully on other species (Aird, 1986; Charland, 1991).

\section{Nerodia s. sipedon}

We used halothane in the open method to anesthetize 70 northern water snakes (54$580 \mathrm{~g}$ ). The righting reflex was lost after 10-30 min (Table 1). Snakes that still responded to stimuli after removal from the jar reached surgical anesthesia if left undisturbed for 10-15 min. It generally took northern water snakes at least 30 min to revive from anesthesia even though we started ventilating them at the beginning of the surgery. Four snakes never recovered from anesthesia, two of which were debilitated snakes from which we were removing the transmitters. One snake had been seized by a predator and was severely wounded. The fourth snake was thin and dehydrated. Disadvantages of this method with northern water snakes include variable induction times and prolonged recovery times. Snakes frequently appeared sedated for several hours following anesthesia. This method should not be used on debilitated snakes. Once experience with this method is obtained, it can consistently provide a 20-30 min period of surgical anesthesia in northern water snakes.

\section{Sistrurus c. catenatus}

We conducted 36 surgeries on a total of 31 eastern massasauga rattlesnakes, including 19 females (9 non-gravid and 10 gravid) and 12 males (97-380 g). Rattlesnakes were anesthetized using a halothane precision vaporizer (Table 1). We used a $5 \%$ halothane concentration to induce anesthesia. Induction times averaged $38 \mathrm{~min}$ but varied widely (range $=18-60 \mathrm{~min}$ ). We used ANCOVA to assess the effects of group (male, gravid female and non-gravid female) and mass on induction time. The interaction term was not significant $(F(2,16)=1.98, p=0.17)$ and was eliminated from the final model. Neither group $(F(2,18)=0.38, p=0.68)$ nor mass $(F(1,18)=0.09, p=0.76)$ was significant in the final model, indicating that sex, female reproductive condition, and mass did not have an effect on induction time. The response to handling of 17 snakes during 21 surgeries was recorded as either passive, active or aggressive. In only one instance was a snake scored as aggressive. Snakes that were passive $(n=12)$ achieved plane of surgery sooner than those that were active $(n=8)$, although this difference (33 min vs. $42 \mathrm{~min}$ ) was not significant $(F(1,18)=3.26, p=0.08)$. Despite our efforts to minimize halothane administration, snake recovery times were often prolonged. In total, 21 snakes were monitored after surgery and most showed only limited recovery (tongue flicking, slight movement) within 30 min of cessation of anesthetic administration. Six snakes were still unresponsive $60 \mathrm{~min}$ after halothane was discontinued, and four snakes took longer than $2.5 \mathrm{hr}$ to recover fully. Nevertheless, in only one of the 36 surgeries did a snake fail to recover from anesthesia. This snake was administered halothane for $60 \mathrm{~min}$ and even then briefly responded to the initial surgical incision. It is perhaps significant that this snake was the only individual scored as aggressive in its response to handling.

\section{DISCUSSION}


Some authors suggest that pre-anesthetic sedation with acepromazine or ketamine be used to achieve more consistent results with inhalant anesthesia (Bennett, 1991). However, use of a pre-anesthetic may increase recovery time. We found that once we obtained experience with inhalant anesthesia in a few snakes, we were able to achieve consistent surgical anesthesia and rapid recoveries with the inhalant agent alone. However, induction times, anesthetic concentrations and guidelines for ventilation that we report are generalizations and should be tailored to the depth of anesthesia of individual snakes.

We found substantial variation within species in how individuals responded to a given anesthetic agent. This variation could be a function of individual differences in stress, condition, age, body temperature, size, or other factors. However, the effects of these factors on the response of snakes to anesthesia have never been investigated so our understanding of this variation is very limited. Our preliminary results with black rat snakes and massasauga rattlesnakes indicated that sex did not affect anesthesia induction time. However, larger female black rat snakes recovered faster from anesthesia than smaller females, although mass had no effect on recovery time for male black rat snakes. This inconsistency of the effect of mass on induction and recovery times in rat snakes suggests that further investigation would be worthwhile to determine whether a real effect exists but is confounded by other factors. For example, the preliminary results we obtained with massasauga rattlesnakes suggested that stress level might influence the effects of the anesthetic. Although the difference was not significant, active rattlesnakes tended to take longer to reach surgical anesthesia than passive rattlesnakes.

Consistent with previous studies (McDonald, 1976; Bonath, 1979; Aird, 1986; Font and Schwartz, 1989; Arena and Richardson, 1990), we also found substantial variation to anesthetic agents among species. For example, the technique we used to anesthetize northern water snakes (halothane in the open method) was inappropriate for use on black rat snakes. This required a trial and error approach to design a technique suitable for black rat snakes, resulting in lost time and two fatalities. At present such an approach is necessary when anesthetizing an individual of a species for which no published information is available. Given our results with three species, and both physiological and practical considerations, we recommend isoflurane as the anesthetic to assess first when working with a species for the first time. All the snakes we anesthetized with isoflurane revived, whereas mortality was unacceptably high with halothane (2/7 for rat snakes, 1/36 for rattlesnakes, and 4/70 for water snakes).

Ideally one would like to be able to predict how different species will respond to different anesthetics. There is insufficient information in the literature at present to determine whether the response to a given agent follows taxonomic lines or is related to other natural history characteristic of different species (e.g., size; aquatic vs. terrestrial vs. arboreal species). Because of the obvious benefits to future researchers of being able to predict which anesthetic will be best for their species, we encourage people with experience anesthetizing different snake species to communicate this information (both positive and negative) when publishing the results of their research. 


\section{ACKNOWLEDGMENTS}

We are grateful to K. Kissner, H. McCracken, J. Svec, and C. Verreault for helping with data collection, and to $\mathrm{D}$. Smith for her advice when we first started anesthetizing snakes. Funding and logistical support for this research was provided by World Wildlife Fund Canada, Parks Canada, Ontario Ministry of Natural Resources, and a NSERC operating grant to PJW. All the research projects we undertook and all the experimental protocols we used had previously been approved by the Carleton University Animal Care Committee.

\section{LITERATURE CITED}

AIRD, S. D.

1986. Methoxyflurane anesthesia in Crotalus: comparisons with other gas anesthetics. Herpetological Review 17:82-84.

ARENA, P. C. AND K. C. RICHARDSON 1990. The relief of pain in cold-blooded vertebrates. Australian Council for the Care of Animals in Research and Teaching News 3:1-4.

BENNETT, R. A. 1991. A review of anesthesia and chemical restraint in reptiles. Journal of Zoo and Wildlife Medicine 22:282-303.

BETZ, T. W. 1962. Surgical anesthesia in reptiles, with special reference to the water snake, Natrix rhombifera. Copeia 1962:284-287.

BONATH, K. 1979. Halothane inhalation anesthesia in reptiles and its clinical control. International Zoo Yearbook 19:112-125.

CHARLAND, M. B. 1991. Anesthesia and transmitter implantation effects of gravid garter snakes (Thamnophis sirtalis and T. elegans). Herpetological Review 22:46-47.

CIOFI, C. and G. CHELAZZI

1991. Radiotracking of Coluber viridiflavus using external transmitters. Journal of Herpetology 25:37-40.

CONCANNON, K. T. 1996. What should you know about anesthetic machines: a review. Veterinary Medicine April:341-348. 
FAGELLA, A. M. AND M. R. RAFFE

1987. The use of isoflurane anesthesia in a water monitor lizard and a rhino iguana. Comparative Animal Practice 1:52-53.

FITCH, H. S. AND H. W. SHIRER

1971. A radiotelemetric study of spatial relationships in some common snakes. Copeia 1971:118-128.

FONT, E. AND J. M. SCHWARTZ 1989. Ketamine as an anesthetic for some squamate reptiles. Copeia 1989:484486.

FRYE, F. L. 1991. Biomedical and Surgical Aspects of Captive Reptile Husbandry, Second edition. Krieger Publishing, Malabar, Florida.

1993. Reptile Clinician's Handbook: a Compact Surgical and Clinical Reference. Krieger Publishing, Malabar, Florida.

HACKENBROCK, C. R. AND M. FINSTER

1963. Fluothane: a rapid and safe inhalation anesthetic for poisonous snakes. Copeia 1963:440-441.

HARVEY-CLARK, C.

1995. Research aspects of anesthesia of reptiles. Canadian Association for Laboratory Animal Science/Association Canadienne pour la Science des Animaux de Laboratoire 29:25-29.

KARLSTROM, E. L. AND S. F. COOK

1955. Notes on snake anesthesia. Copeia 1955:57-58.

MCDONALD, H. S.

1976. Methods for the Physiological Study of Reptiles. Pages 19-126 in Biology of the reptilia, Vol. 5, (C. Gans and W. R. Dawson, eds). Academic Press, New York.

REINERT, H. K< 1992. Radiotelemetric field studies of pitvipers: data acquisition and analysis. Pages 185-197 in Biology of the Pitvipers, (J. A. Campbell and E. D. Brodie, eds). Selva, Tyler.

AND D. CUNDALL

1982. An improved surgical implantation method for radio-tracking snakes. Copeia 1982:702-705. 
WEATHERHEAD, P. J. AND F. W. ANDERKA

1984. An improved radio transmitter and implantation technique for snakes. Journal of Herpetology 18:264-269. 